\title{
Perceived Freedom in Leisure Scale-25: Testing the construct validity for university students ${ }^{1}$
}

\author{
Tennur Yerlisu Lapa ${ }^{2}$ \\ Evren Tercan Kaas ${ }^{3}$
}

\begin{abstract}
Leisure behaviour is an important study area of the literature recently. In apprehending leisure behaviour, perceived freedom in leisure is a significant dimension. The aim of the study is to test validity of "Perceived Freedom in Leisure Scale (PFLS)" by confirmatory factor analysis (CFA). Study group of this descriptive research consists of 228 university students. Reliability was calculated by internal consistency coefficient Cronbach's Alpha. As a result of the CFA, modification indexes were examined and items with high error covariance's were matched (e9-e10, e13-e14, e16-e20). After the modification the results were as follows: $\chi^{2} / d f\left(\chi^{2} / d f=1.56\right)$ and other fit indexes: AGFI $=0.85$, GFI $=0.87$, NFI $=0.95$, TLI $=0.98$, $\mathrm{CFI}=0.98$ and RMSEA $=0.050$. Cronbach's alpha reliability coefficient was found as 0.93 . Consequently after the findings, PFLS could be declared to be used in leisure research as a valid and reliable measurement tool with its 25 items and one factor structure.
\end{abstract}

Keywords: Perceived freedom in leisure; university students; construct validity.

(Extended English summary is at the end of this document)

\section{Serbest Zamanda Alg1lanan Özgürlük Ölçeği-25: Üniversite öğrencileri için yap1 geçerliğinin sınanması}

Özet

Serbest zaman davranışının anlaşılmasında serbest zamanda alg1lanan özgürlük konusu önemli bir boyut olarak görülmektedir. Bu çalışmanın amacı, "Serbest Zamanda Algılanan Özgürlük Ölçeği (SZAÖÖ)"nin geçerliğinin doğrulayıcı faktör analizi (DFA) ile sınanmasıdır. Araştırmanın çalışma grubu 228 üniversite öğrencisinden oluşturmaktadır. Ölçeğin güvenirliğini belirlemek için ise Cronbach alfa iç tutarlık katsayısı hesaplanmıştır. DFA sonucu, modifikasyon endekslerine bakılarak yüksek hata kovaryanslanna sahip maddeler birbirleri ile eşleştirilmiştir (e9-e10, e13-e14, e16-e20). Yapilan modifikasyon endekslerine göre $\chi^{2} / d f$ $\left(\chi^{2} / d f=1.56\right)$ ve diğer uyum indeks değerleri: $\mathrm{AGFI}=0.85$, GFI $=0.87, \mathrm{NFI}=0.95$, TLI $=0.98$, CFI $=0.98$ ve RMSEA $=0.050$ olarak tespit edilmiştir. Ölçeğin güvenirlik kat sayısı 0.93 olarak saptanmıştır. Araşturma sonucu, 25 madde ve tek faktörden oluşan SZAÖÖ'nin geçerli ve güvenilir bir ölçüm aracı olduğu söylenebilir.

Anahtar Kelimeler: Serbest zamanda alg1lanan özgürlük; üniversite öğrencileri; yapı geçerliği.

${ }^{1}$ This paper was presented as oral presentation at "World Congress of Sport Sciences Researches" on November $23^{\text {th }}$ $26^{\text {th }}, 2017$ in Manisa

${ }_{2}^{2}$ Assoc. Prof. Dr., Akdeniz University, Faculty of Sport Sciences, Department of Recreation, tennur@akdeniz.edu.tr ${ }^{3}$ Assoc. Prof. Dr., Akdeniz University, Faculty of Sport Sciences, Department of Sport Management, evrentercan@akdeniz.edu.tr 
Yerlisu Lapa, T., \& Tercan Kaas, E. (2019 Serbest Zamanda Algilanan Özgürlük Ölçeği-25: Üniversite öğrencileri için yap1 geçerliğinin sinanmas1. Journal of Human Sciences, 16(4), 1071-1083. doi:10.14687/ihs.v16i4.5860

\section{Giriş}

Serbest zaman davranışı, literatürde yakın dönemin önemli bir çalışma alanını oluşturmaktadır. Serbest zaman davranışının anlaşılmasında serbest zamanda algilanan özgürlük konusu önemli bir boyut olarak görülmektedir (Wu ve ark., 2010). Çağdaş toplumların en temel değerlerinden biri olan özgürlük (Naito, 2007) kavramı ile serbest zaman ilişkisi Aristotle'ın serbest zamanı çalışmanın gerekliliklerinden bağımsız olmak olarak tanımlamasından beri incelenmiş olup serbest zamanın özel bir amacı, erdemli bir eylemi olduğu düşünülmüştür (Hemingway, 1996). Alg1lanan özgürlük kavramının insan davranışlarını etkileyen bir kontrol değişkeni olarak tespiti Heider tarafından genişletilmiş ve Heider algilanan özgürlügü bireylerin davranışları üzerinde tahmin yürütmek için kullanışlı bir araç olarak önermiş ve bireylere ilişkin davranışlarının onların algılanan özgürlük duygusuyla belirlendiğini açıkça belirtmiştir (Wu ve ark., 2010). Algılanan özgürlük kavramı, Ellis ve Witt (1984) ve de Neulinger tarafindan serbest zamanin temel bir kriteri olarak ifade edilmiss ve Neulinger tarafindan "Bireyin yaptı̆̆ını isteyerek ve kendi seçimiyle yaptığı bir durum" olarak tanımlanmıştır (Siegenthaler ve O’Dell, 2000). Algılanan özgürlük ile serbest zaman ilişkisi ampirik olarak da test edilmiş, Iso-Ahola tarafindan yapılan çalışmalarda katılımcıların serbest zaman tecrübelerinin kalitesini derecelendirmelerinde algılanan özgürlük düzeyinin belirleyici olduğu ya da katılım sağlama veya sağlamama hususunda alg1ladıkları özgürlüğün belirleyici olduğu tespit edilmiştir (Ellis ve Witt, 1984).

\section{Serbest Zamanda Algılanan Özgürlük}

Serbest zamanda algilanan özgürlük Witt ve Ellis tarafindan bireyin tatmin edici serbest zaman deneyimlerine katıllımını engelleyici kısıtlardan bağımsız olma düzeyi olarak belirlenmiştir (Carter, 1995). Serbest zamandaki Özgürlük Neulinger tarafindan serbest zamanda algılanan yetkinlik, serbest zamanda algilanan kontrol ve algılanan içsel motivasyon gibi üç kavramla ilişkili görülmüştür (Stelzer, 2000). Neulinger, serbest zamanda alg1lanan özgürlükten söz ederken algıların önemine de vurgu yapmıştır (Siegenthaler ve O’Dell, 2000). Ellis ve Witt (1984) serbest zamanın sosyal psikolojisi, atfetme kuram1, oyun ve motivasyon gibi kavramlara yönelik literatürü incelemiş ve serbest zamanda algılanan yetkinlik, serbest zamanda algılanan kontrol, serbest zaman ihtiyaçları, serbest zaman tecrübelerinde katılımın derinliği ve oyunbazlık alt ölçeklerinden oluşan 95 soruluk bir ölçek geliştirmiştir. Serbest zamanda algılanan yetkinlik alt boyutundaki temel varsayım bireyin serbest zaman aktivitelerine başarllı katılımının bireye seçtiği aktivitelere özgürce katılma duygusu vereceği varsayımıdır. Serbest zamanda algılanan kontrol alt boyutu ise bireylerin aktivitelerin başlangıcını, sürecini ve çıktlarını etkileme becerilerine sahip olduklarında özgürlük algısının mevcut olacağ1 kabulüne dayanmaktadır. İçsel motivasyon alt boyutu algılanan özgürlüğün önemli bir bileşeni olup (Deci, 1975), bireylerin çeşitli davranışları zevk, merak veya rahatlama gibi içsel nedenlerden gösterdiğini ifade etmektedir. Serbest zaman ihtiyaçları alt ölçeği, katıllımcıların bireysel ve içsel ihtiyaçlarını tatmin etme düzeyini göstermektedir. Bu alt ölçekler içinde davranışsal boyutu ön plana çıkaran ölçek ise oyunbazlık alt ölçeği olup bireyin diğerlerinin normatif veya durumsal beklentilerine uymadan beklenmedik davranışları gösterebilme özgürlüğünü ifade etmektedir (Ellis ve Witt, 1984). Bu ölçekler ayrıca Serbest Zaman Teşhis Bataryasının da birinci bölümünü oluşturmaktadır. Katılımcıların ve kullanıcıların daha kısa zamanda bitirilecek bir ölçek talebi ve lise öğrencileriyle yetişkinlere yönelik ölçeklere duyulan ihtiyaç sonucu algılanan özgürlük ölçeğinin kısa formu geliştirilmiştir. Bu ölçek geliştirilirken, serbest zamanda alg1lanan yetkinlik ölçeğinden beş, serbest zamanda alg1lanan kontrol ölçeğinden on, serbest zaman ihtiyaçları ölçeğinden altı, serbest zaman katılımının derinliği ölçeğinden ise dört madde alınmıştır. 25 sorudan oluşan bu ölçeğin hem lise öğrencileri hem de yetişkinlere yönelik uyarlaması bulunmaktadır (Witt ve Ellis, 1985). Gerek Alg1lanan Özgürlük Ölçeği, gerek Algılanan Özgürlük Ölçeği Kısa Formu gerekse serbest zaman teşhis bataryasının geliştirilmesi literatürde serbest zamanda algılanan özgürlük konusundaki çalışmaları arttırmıştır. 
Yerlisu Lapa, T., \& Tercan Kaas, E. (2019 Serbest Zamanda Algilanan Özgürlük Ölçeği-25: Üniversite öğrencileri için yap1 geçerliğinin sinanması. Journal of Human Sciences, 16(4), 1071-1083. doi:10.14687/jhs.v16i4.5860

\section{Literatürde Serbest Zamanda Alg1lanan Özgürlük}

Munson, 1993'de Ohio' da lise öğrencilerine yönelik olarak serbest zamanda algılanan özgürlük ile toplumsal hizmet rollerine bağlılık arasındaki ilişkinin sorgulandığı bir çalışma yürütmüş ve Witt ve Ellis (1985) tarafindan geliştirilmiş olan ve adölesanlara yönelik hazırlanan 25 maddelik ölçeğin A uyarlaması kullanılarak serbest zamanda alg1lanan özgürlük ölçülmüştür. Buna göre algilanan özgürlük düzeyleri daha yüksek olan bireylerde toplumsal hizmet rollerine bağlll1k düzeyleri daha yüksek elde edilmişken okul, çalışma ve aile içi rollerle ilgili bağlllık gruplar arasında farksız bulunmuştur. Meksika kökenli Amerikalı adölesanlarda algılanan özgürlük ve aktivite katılımının etkisi araştırılmış ve Witt ve Ellis’in (1985) 25 maddelik ölçeği uygulanmıştır. Sonuçlarda aktivite katılımı ve algılanan özgürlük arasında güçlü pozitif yönde bir korelasyon olduğu, kız çocuklarında algılanan yetkinliğin düşük olmasının aktivite katılımını düşürdüğü, oğlan çocuklarında ise ihtiyaçları karşılayamama durumunun aktivite katılımını düşürdüğgü tespit edilmiştir (Guinn ve ark., 1996). Rekreasyon ve Serbest Zamana Giriş dersleri alan üniversite öğrencileri ve aile üyelerine yönelik olarak gerçekleştirilen bir çalışmada serbest zamanda algılanan özgürlük, serbest zaman tutumu ve serbest zaman tatmini incelenmiş, algılanan özgürlük Witt ve Ellis (1985) tarafindan geliştirilmiş olan 25 maddelik ölçekle test edilmiştir. Aile bireylerinin bazıları arasında serbest zamanda algılanan özgürlük açısından benzer sonuçlar elde edildiği görülmüştür (Siegenthaler ve O’Dell, 2000). Suçlu gençlere yönelik yapılan bir çalışmada serbest zaman motivasyonu, serbest zaman tatmini ve serbest zamanda algılanan özgürlük ilişkileri incelenmiş, Witt ve Ellis (1985) tarafindan adölesanlara yönelik olarak hazırlanan serbest zamanda algılanan özgürlük ölçeğinin kısa formunun A versiyonu uygulanmıstır. Burada motivasyon ve tatminle serbest zamanda algilanan özgürlük arasında negatif bir korelasyon saptanmıştur (Munchua ve ark., 2003). Koordinasyon sorunu olan 10-13 yaşları arasındaki çocuklarda yapılan bir çalışmada serbest zamanda algılanan özgürlüğün fiziksel koordinasyon becerisi, yaşam tatmini ve fiziksel aktivite katılımı ilişkilerinde arac1 olan potansiyel bir mekanizma oluşu araşturılmış, burada Witt ve Ellis (1985) tarafindan adölesanlara yönelik olarak hazırlanan serbest zamanda algilanan özgürlük ölçeğinin kısa formunun A uyarlaması uygulanmıştır. Bulgulara göre serbest zamanda algılanan özgürlüğün fiziksel beceriyle, yaşam tatmini ve takım sporlarına katılım arasındaki ilişkilerde aracı olduğu belirtilmiştir (Poulsen ve ark., 2007). Yine koordinasyon sorunu olan 10-13 yaşları arasındaki çocuklarda yapılan bir başka çalışmada da, motor beceri, serbest zamanda algılanan özgürlük, takım sporlarına katılım, yalnızlık ve yaşam tatmini modellenmiş, serbest zamanda algılanan özgürlük yine aynı şekilde ölçülmüş ve algılanan özgürlük ve takım sporlarına katılımın bu değişkenler arasındaki ilişkilerde aracılık yaptı̆̆ belirlenmiştir (Poulsen ve ark., 2008). Kim (2010) üniversite öğrencilerinin katılımc1 olduğu bir çalışmada sosyal bilişsel değişkenler ve serbest zamanın sübjektif algılanışı ve sübjektif iyi oluş kavramları arasındaki ilişkiyi incelemiş, sosyal bilişsel teorinin serbest zaman ve sübjektif iyi oluşu incelemede uygun bir yapı oluşturduğu sonucuna varmıştır. Burada alg1lanan özgürlük içsel tatmin gibi sosyal bilişsel değişkenlerin içinde yer almıştır ve Witt ve Ellis’in (1985) geliştirdiği 25 maddelik ölçek kullanılmıştır.

Serbest zamanda algılanan özgürlük konusu ülkemizde de irdelenmiş, Witt ve Ellis (1985) tarafindan geliştirilen ölçek dilimize adapte edildikten sonra üniversite öğrencilerine uygulanmış, rekreatif aktivitelere katılım ve demografik özelliklere göre irdelenmiş, sportif, sanatsal ve kültürel aktivitelere aktif katılımın algılanan özgürlük düzeyini arttırdığı ortaya konmuştur (Yerlisu Lapa ve Ağyar, 2012). Belediyelere ait parklarda rekreasyonel spor aktivitelerine katılan kadınlarda yapılan bir çalışmada serbest zamanda algılanan özgürlük, yaşam tatmini ve serbest zaman tatmini arasında anlamlı ilişkiler saptanmıştır (Agyar, 2014). Yine benzer bir konuda kadın ve erkek katılımcılara yönelik olarak yapılan bir çalışmada ise aynı ölçek kullanılmış ve serbest zaman tatmini, yaşam tatmini ve serbest zamanda algılanan özgürlük arasında pozitif yönde anlamlı bir ilişki saptanmışır (Yerlisu Lapa, 2013). Spor bilimleri alanında eğitim gören üniversite öğrencilerinin serbest zamana yüklediği anlam ve algılanan özgürlük düzeylerini ele alan bir başka çalışma sonuçları ise; serbest zaman anlamını oluşturan aktif-pasif katulım, sosyal etkileşim, algılanan yetkinlik ve serbest zamanın varlığ1 alt boyutları ile serbest zamanda algılanan özgürlügün pozitif yönde anlamlı korelasyona 
Yerlisu Lapa, T., \& Tercan Kaas, E. (2019 Serbest Zamanda Algilanan Özgürlük Ölçeği-25: Üniversite öğrencileri için yap1 geçerliğinin sinanması. Journal of Human Sciences, 16(4), 1071-1083. doi:10.14687/ihs.v16i4.5860

sahip olduğu görülmektedir (Harmandar Demirel ve ark., 2017).

Türkiye'de serbest zaman ve rekreasyon ile ilgili çalışmaların henüz az ya da yeni olması özellikle ölçek geliştirme ve ölçek adaptasyon çalışmalarına duyulan ihtiyacı arttırmaktadır (Yerlisu Lapa ve ark., 2018). Kültüre özgü ölçme araçlarının geliştirilmesi daha çok tercih edilen bir yöntem olmasına karşın araştırmacıların geliştirmek istediği psikomoterik özelliklerle ilgili alan uzmanlarının sayısındaki yetersizlik onları adaptasyon çalışmalarına yönlendirmektedir (Büyüköztürk ve ark., 2014, s. 105). Bu durum ülkemizdeki araştırmacıların ölçek geliştirme çalışmalarından daha fazla ölçek adaptasyon çalışmalarına yönelmesinin nedenleri arasında görülebilir. Witt ve Ellis (1985) tarafindan geliştirilen, Yerlisu Lapa ve Ağyar (2011) tarafindan Türkçe adaptasyonu yapılan "Serbest Zamanda Algılanan Özgürlük Ölçeğil" de bu çalışmalardan biridir. Ancak bilimin durağan bir süreç olmadığ göz önüne alındığında gerek araştırmacıların bakış açılarındaki değişiklikler gerekse teknolojik anlamda gelişimlere dayalı olarak istatistiksel analizlerde kullanılan tekniklerin çeşitlenmesi ve kullanılırlı̆̆ı artmıştır. Bu durum bazı uyarlama çalışmalarının yeniden adaptasyon edilme zorunluluğunu da beraberinde getirmektedir (Spielberger ve ark., 2017). Bu nedenle daha önce adaptasyonu gerçekleştirilmiş olan bu ölçeğin, yukarıdaki açıklamalar dahilinde ve ölçmeye konu olan özelliğinde zamanla kültürel anlamda değişikliklere yol açacağı düşüncesi ile yeniden adapte edilmesinin uygun olacağı düşünülmüştür.

\section{Yöntem}

\subsection{Araştırmanın Modeli}

Bu araştırma yapısalcı bir bakış açısına sahip olup ilişkisel bir çalışmadır (Günbayı ve Sorm, 2018). İlişkisel araştırmalar iki veya daha fazla değişken arasındaki ilişkiyi incelemektedir. Araştırmacılar bu ilişkileri incelerken değişkenlere müdahalede bulunulmaz bunun yerine elde edilen sonuçlar aracılığı ile değişkenler arasındaki neden-sonuç ilişkilerine yönelik ipuçları sunarlar (Büyüköztürk ve ark., 2014).

\subsection{Evren ve Örneklem}

Betimsel araştırma modelindeki araştırmanın çalışma grubunu, 2016-2017 eğitim-öğretim yılında, Akdeniz üniversitesinde öğrenim gören 105’i kadın ve 123’ü erkek toplam 228 üniversite öğrencisi oluşturmaktadır. Araştırmaya katılan öğrencilerin yaşlan 18-26 arası değişmekte olup yaş ortalamaları 19.82 1.41 'dir. Örneklem seçiminde amaçlı örnekleme yöntemlerinden kolay ulaşılabilir örnekleme yöntemi kullanılmıştır. Kolayda ulaşıllı örnekleme tekniğinin seçilmesindeki temel amaç, araştırmacının iş gücü, para ve zaman kaybını azaltmaktır (Ravid, 1994).

\subsection{Veri Toplama Araçlanı}

Araştırmada Witt ve Ellis (1985) tarafindan geliştirilen, Yerlisu Lapa ve Ağyar (2011) tarafindan Türkçeye adaptasyonu yapılan "Serbest Zamanda Alg1lanan Özgürlük Ölçeği (SZAÖ)" veri toplama aracı olarak kullanılmıştır. Orijinal ölçek, 25 madde ve tek faktörden oluşmaktadır. Serbest zamanda algılanan özgürlük ölçeği; serbest zamanda algılanan yetkinlik, algılanan kontrol ve algılanan içsel motivasyonu ölçmeye yönelik tasarlanmıştur. Ölçeğin değerlendirmesi 5'li Likert formunda; kesinlikle katılmıyorum (1), katılmıyorum (2), kararsızım (3), katılıyorum (4), kesinlikle katılıyorum (5) şeklindedir. Geliştirilen ölçeğin orijinal kültürdeki denemelik maddelerine ulaşılamadığı için açımlayıcı faktör analizi kullanılmamış bunun yerine ölçek adaptasyon sürecinin aşamaları titizlikle değerlendirilerek ortaya konan yapının doğrulayıcı faktör analizi ile kültürümüze uygunluğu sinanmıştır.

\section{4. Ö1çek Adaptasyon Süreci}

Ölçeğin adaptasyon sürecinde Hambleton ve Patsula (1999)'in ölçek adaptasyon çalışmalarının nasıl yapılması gerektiğine ilişkin ifade ettikleri aşamalar takip edilmiştir. 1- Öncelikli olarak yeni bir ölçek geliştirilmesinin mi yoksa var olan bir ölçeğin adapte edilmesinin mi daha uygun olacağ1 tartışılmış; 2- Uyarlama yapılmasının daha uygun olacağı düşüncesi ile ölçeği geliştiren 
Yerlisu Lapa, T., \& Tercan Kaas, E. (2019 Serbest Zamanda Algilanan Özgürlük Ölçeği-25: Üniversite öğrencileri için yap1 geçerliğinin sinanması. Journal of Human Sciences, 16(4), 1071-1083. doi:10.14687/jhs.v16i4.5860

araştırmacılardan gerekli izinler alınmış; 3- Orijinal kültür ile çalışılacak olan kültürde ölçülecek özelliğe ilişkin yapının eşitliği sağlanmış; 4- Her iki kültüre aşina olan ve her iki dili iyi düzeyde bilen çevirmenler seçilmiş; 5- Ölçeğin çevrilmesi ve uyarlamasına geçilmiş; 6- Çeviriden sonra ölçeğin uyarlanmış hali gözden geçirilmiş ve ilgili düzenlemeler yapılmış; 7- Uyarlaması yapılan ölçeğin deneme grubuna uygulaması yapılmış; 8- Deneme grubunda sınanan ölçeğin daha büyük bir grupta uyarlanması yapılmış ve son olarak; 9- Geçerlik ve güvenirlik analizleri yapılmıştır.

\subsection{Uygulama}

Orijinal ölçek ve ölçme aracına ilişkin uygulama ve puanlama yönergeleri her iki kültüre aşina olup iyi düzeyde İngilizce bilen iki bağımsız araştırmacı tarafından çevrilmiştir. Çevirinin ardından rekreasyon alanında uzman iki araştırmacı, İngilizce diline hakim bir araştırmacı, Türkçe dil uzmanı ve ölçme ve değerlendirme uzmanından oluşan bir ekip tarafindan yapılan çevirilerin kuramsal açıdan ve anlam bakımından uygunluğu tartısılmıştır. Ölçeğe ilişkin dilsel, kültürel ve kuramsal olarak uygun olduğu düşünülen maddeler tercih edilmiş, semantik düzenlemeler yapılmıştır. Ölçeğe son halinin verilmesi ile birlikte bir sonraki aşamaya geçilmiş ve Türkçe dilinden orijinal dile geri çeviri yapılmıştır. Geri çeviri sürecinde araştırmacıların yalnızca dil yetkinliği değil aynı zamanda alan bilgisine sahip olması gözetilmiş ve geri çeviri esnasında karşılaşılabilecek kuramsal terimler ile ilgili yetersizliklerin giderilmesi sağlanmıştır. Geri çevirme işlemi yapılan ölçek metni ile orijinal ölçek metni arasındaki söz konusu farklılıkların önemli düzeyde olmadığı saptanarak Türkçe çevirme işleminin tamamlanmasına karar verilmiştir. Türkçe çeviri işleminin tamamlanmasından sonra dil geçerliğinin test edilmesi aşamasına geçilmiştir. Dilsel eşdeğerliğin sağlanması hususunda iki farklı yöntemden söz edilmektedir. Bunlardan biri uzman görüşü diğeri ise istatistiksel tekniklerdir. Eğer ölçeğin uygulanacağı örneklem her iki dile de hakim değilse o zaman uzman görüşüne başvurulmaktadır (Seçer, 2015). Ancak yapılan çalışmanın örneklemi üniversite öğrencilerinden oluştuğu için her iki dile de hakim 21 öğrenci dilsel eşdeğerlik için karşılaştırılmıştır. Bu aşamada ilk olarak öğrencilere ölçeğin orijinal formu uygulanmış bu uygulamadan 15 gün sonra yine aynı kişilere ölçeğin Türkçe formu uygulanmıştır. Her iki uygulamadan elde edilen puanlar arasındaki pearson momentler çarpımı korelasyon kat sayısı hesaplanmış ve iki uygulamadan elde edilen puanların kararllğ1 ortaya konulmuştur ( $\mathrm{r}=0.93$; $\mathrm{p}=0.000)$. Pilot uygulama 2016-2017 y1l güz döneminde, spor bilimleri fakültesinde öğrenim gören 35 öğrenciye uygulanmış ve uygulama esnasında ölçeğin cevaplanmasına ilişkin bir süre belirlenmemiştir. Bu uygulamadaki amaç ölçek sorularının yanıtlanması için ihtiyaç duyulan sürenin belirlenmesidir. Uygulama süresince soruların anlaşıllırlığına ilişkin öğrencilerden gelen dönütler dikkate alınarak gerekli düzenlemeler yapılmış ve ölçeğin nihai formu hazırlanmıştır (Tablo 1). Bu aşamadan sonra dilsel eşdeğerliğin sağlandığ1 varsayılarak ölçeğe ilişkin geçerlik ve güvenirlik çalışmaları yürütülmüştür.

\section{Tablo 1. Serbest Zamanda Algılanan Özgürlük Ölçeği}

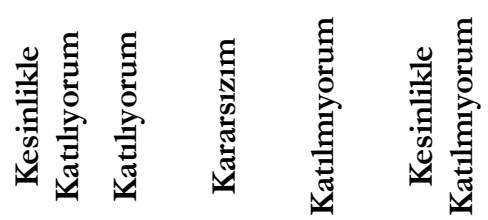

1. Katıldığım rekreasyon aktiviteleri kendimi önemli hissetmemi sağlar.

2. Çok sayıda eğlenceli rekreasyon aktivitesi biliyorum.

3. Rekreasyon aktivitelerini beraber yaptığım kişilerin becerilerini geliştirebilecek şeyler yapabilirim.

4. Yapmak istediğim tüm rekreasyon aktivitelerini yapabilecek kadar iyiyim.

5. Bazen, bir rekreasyon aktivitesi sırasında her şeyi yapabileceğimi hissettiğim kısa anlar olur.

$\begin{array}{lllll}5 & 4 & 3 & 2 & 1 \\ 5 & 4 & 3 & 2 & 1 \\ 5 & 4 & 3 & 2 & 1 \\ 5 & 4 & 3 & 2 & 1 \\ 5 & 4 & 3 & 2 & 1\end{array}$


Yerlisu Lapa, T., \& Tercan Kaas, E. (2019 Serbest Zamanda Alg1lanan Özgürlük Ölçeği-25: Üniversite öğrencileri için yap1 geçerliğinin sinanması. Journal of Human Sciences, 16(4), 1071-1083. doi:10.14687/ihs.v16i4.5860

6. Benim için yapabileceğim bir rekreasyon aktivitesini seçmek kolaydır.

7. Rekreasyon aktiviteleri sırasında diğer insanların beni daha çok beğeneceği şeyler yapabilirim.

8. Rekreasyon aktiviteleri diğer insanları tanımama yardımcı olur.

9. Bir rekreasyon aktivitesini istediğim kadar eğlenceli hale getirebilirim.

10. Bir aktivite sırasında diğer insanların daha fazla eğlenmesini sağlayacak şeyler yapabilirim.

11. Genelde rekreasyon aktivitelerini kiminle yapacağıma kendim karar veririm.

12. Diğer insanlarla birlikte yaptı̆̆ım aktivitelerde iyiyim.

13. Hemen hemen yaptığım tüm rekreasyon aktivitelerinde iyiyim.

14. Yaptığım rekreasyon aktivitelerinde yaratıcı olabilirim.

15. Rekreasyon aktivitelerini herkes için eğlenceli hale getirebilirim.

16. Rekreasyon aktivitelerim sırasında, sıklıkla her şeyin iyi gittiği anlar olur ve çok heyecanlanırım.

17. İstemeseler de çoğunlukla insanların benimle rekreasyon aktivitelerini yapmalarını sağlarım.

18. Hemen hemen her aktiviteyi kendim için eğlenceli hale getirebilirim.

19. Yeni arkadaşlar edinmeme yardımcı olan rekreasyon aktivitelerine katilirım.

20. Rekreasyon aktivitelerini yaparken iyi şeylerin olmasını sağlarım.

21. Rekreasyon aktivitelerini yaparken kendimi güçlü ve kontrol sahibi hissettiğim zamanlar olur.

22. İnsanların benimle aktivite yapmaktan hoşlanacağı şeyler yapabilirim.

23. Sıkıntılı iken sakinleşmek için rekreasyon aktivitelerine katılabilirim.

24. Rekreasyon aktivitelerini yaparken heyecanlanırım.

25. Rekreasyon aktivitelerini yaparken genelde eğlenirim.

$\begin{array}{lllll}5 & 4 & 3 & 2 & 1 \\ 5 & 4 & 3 & 2 & 1 \\ 5 & 4 & 3 & 2 & 1 \\ 5 & 4 & 3 & 2 & 1 \\ 5 & 4 & 3 & 2 & 1 \\ 5 & 4 & 3 & 2 & 1 \\ 5 & 4 & 3 & 2 & 1 \\ 5 & 4 & 3 & 2 & 1 \\ 5 & 4 & 3 & 2 & 1 \\ 5 & 4 & 3 & 2 & 1 \\ 5 & 4 & 3 & 2 & 1 \\ 5 & 4 & 3 & 2 & 1 \\ 5 & 4 & 3 & 2 & 1 \\ 5 & 4 & 3 & 2 & 1 \\ 5 & 4 & 3 & 2 & 1 \\ 5 & 4 & 3 & 2 & 1 \\ 5 & 4 & 3 & 2 & 1 \\ 5 & 4 & 3 & 2 & 1 \\ 5 & 4 & 3 & 2 & 1 \\ 5 & 4 & 3 & 2 & 1\end{array}$

\subsection{Verilerin Analizi}

Yapılan çalışmada veri analizi için LISREL paket programları kullanılmıştur. Verilerin analizinde, betimsel istatistikler iç tutarlılık güvenirlik katsayısı (Cronbach Alfa) analizi, serbest zamanda algılanan özgürlük ölçeğinin tek faktörlü yapısını ortaya koymak amacıyla DFA analizi kullanılmıştır. DFA, gizil değişkenler ile oluşan bir kuramın test edilmesinde kullanılan bir tekniktir (Tabachnick ve Fidell, 2007). DFA analizi bir kavrama ilişkin tanımlanmış ve sınırlandırılmış bir yapıyı doğrulamak için kullanılmaktadır (Kline, 2005). Ancak araştırmacıların faktör analizi yapmadan önce ortaya çıkacak problemleri asgari düzeye indirmek için belli başlı temel sayıltıları sinanması gerekmektedir. Bu sayıltılar araştırmacıların kullandığı veri setine ilişkin örneklem büyüklüğü, normallik ve doğrusallık, çoklu bağlantı ve tekillik ile kayıp ve uç değerlerdir.

Normallik varsayımının karşılanıp karşılanmadığını saptamak amacıyla mod, meydan ve aritmetik ortalama değerleri karşılaştırılmış, basıklık - çarpıklık katsayıları ile Kolmogorov-Smirnov testi sonuçları değerlendirilmiş ve son olarak histogram eğrisi incelenmiştir. İncelemeler sonucunda basıklık ve çarpıklık katsayılarının -1.5 ile +1.5 aralığında olduğu; mod medyan ve aritmetik ortalama değerlerinin birbirine yakın olduğu ve histogram eğrisindeki dağılımların normale yakın olduğu tespit edilmiştir. Bununla birlikte Kolmogorov- Smirnov testi sonuçları manidar değildir $(p=0.065)$. Bu sonuçlar dahilinde verinin büyük oranda normal dağıldığı ifade edilebilir (Tabachnick ve Fidell, 2007; Rosenthal ve Rosnow, 2008). 
Yerlisu Lapa, T., \& Tercan Kaas, E. (2019 Serbest Zamanda Algilanan Özgürlük Ölçeği-25: Üniversite öğrencileri için yap1 geçerliğinin sinanması. Journal of Human Sciences, 16(4), 1071-1083. doi:10.14687/ihs.v16i4.5860

Faktör analizi için gerekli olan bir diğer koşul ise örneklem büyüklügüdür. Alanyazında örneklem büyüklügünün kaç olması gerektiğine ilişkin farklı bilgiler bulunmasına karşın 200 kişilik bir verinin analiz yapmak için orta derecede iyi olduğu ifade edilmektedir (Comrey ve Lee, 1992). Örneklem büyüklüğüne ilişkin bir diğer görüş ise, örneklem büyüklüğ̈nnün madde ve faktör sayısına ilişkin bağıl ölçütlere dayalı olarak tahmin edilmesi gerektiğidir (Kline, 1994). Buna göre madde sayısının 10 katı kadar örneklem kullanılmasının faktör analizi için uygun olacağı ifade edilmektedir. Örneklem büyüklüğü ele alındığında faktör analizi yapmaya uygun bir örnek olduğu ifade edilebilir. Çalışmanın bir sonraki sayıltısı kayıp değerlerler ile uç değerlerin taramasıdır. Uç değerlerin tespit edilmesi için mahlonobis uzaklığından yararlanılmıs ve uç değer olduğu tespit edilen veriler analiz dışında bırakılmıştır. Bununla birlikte kayıp verilerin sistematik bir şekilde dağılmadığı tespit edilerek kayıp veri oranının \%0 ile \%1.3 arasında değiştiği görülmüştür. Böylelikle orjinal veri seti 357 kişiden oluşurken analiz 247 kişi ile tamamlanmıştır.

Çok değişkenli normallik, doğrusallık ve eş varyanslılık sayıltılan her grup için incelenmiştir. Çok değişkenli normallik ve doğrusallık için saçılım diyagramlanı incelenmiştir. Elde edilen saçılım diyagramlanının elips şeklinde olduğu ve çok değişkenli normallik ve doğrusallık varsayımının sağlandığı tespit edilmiştir. Doğrusallık sayıltısı çok değişkenli analizlerde önemli bir saylltı olarak görülmektedir (Tabachnick ve Fidell, 2007).

Faktör analizine ilişkin son sayıltı ise çoklu bağlant problemidir. Bu bağlamda VIF değerinin 10'dan küçük olduğu, çoklu bağlantı probleminin olmadığı saptanmıştır.

Temel sayıltıların karşılanmasından sonra DFA yapılmıştır. DFA analizinde birden fazla uyum indeksi yer almaktadır. DFA'de karar vermek için birden fazla uyum indeksi değerlendirilmektedir. Bu uyum indekslerinin neler olduğu, kabul edilebilir ve mükemmel uyum indekslerinin neler olduğu Tablo 2'de verilmektedir.

Tablo 2. Yapısal Eşitlik Modeli Araştırmalarında Kullanılan Uyum İndekslerine İlişkin Mükemmel ve Kabul Edilebilir Uyum Ölçütleri

\begin{tabular}{lll}
\hline Uyum Indeksleri & Mükemmel Uyum Ölçütleri & Kabul Edilebilir Uyum Ölçütleri \\
\hline${ }^{1} \chi 2 / \mathrm{sd}$ & $0 \leq \chi 2 / \mathrm{sd} \leq 2$ & $2 \leq \chi 2 / \mathrm{sd} \leq 3$ \\
\hline${ }^{2} \mathrm{AGFI}$ & $.90 \leq \mathrm{AGFI} \leq 1.00$ & $.85 \leq \mathrm{AGFI} \leq .90$ \\
\hline${ }^{3} \mathrm{GFI}$ & $.95 \leq \mathrm{GFI} \leq 1.00$ & $.90 \leq \mathrm{GFI} \leq 95$ \\
\hline${ }^{3} \mathrm{CFI}$ & $.95 \leq \mathrm{CFI} \leq 1.00$ & $.90 \leq \mathrm{CFI} \leq .95$ \\
\hline${ }^{3} \mathrm{NFI}$ & $.95 \leq \mathrm{NFI} \leq 1.00$ & $.90 \leq \mathrm{NFI} \leq .95$ \\
\hline${ }^{3} \mathrm{NNFI}(\mathrm{TLI})$ & $.95 \leq \mathrm{NNFI}(\mathrm{TLI}) \leq 1.00$ & $.90 \leq \mathrm{NNFI}(\mathrm{TLI}) \leq .95$ \\
\hline${ }^{3} \mathrm{RFI}$ & $.95 \leq \mathrm{RFI} \leq 1.00$ & $.90 \leq \mathrm{RFI} \leq .95$ \\
\hline${ }^{3} \mathrm{IFI}$ & $.95 \leq \mathrm{IFI} \leq 1.00$ & $.90 \leq \mathrm{IFI} \leq .95$ \\
\hline${ }^{4} \mathrm{RMSEA}$ & $.00 \leq \mathrm{RMSEA} \leq .05$ & $.05 \leq \mathrm{RMSEA} \leq .08$ \\
\hline${ }^{4}$ SRMR & $.00 \leq \mathrm{SRMR} \leq .05$ & $.05 \leq \mathrm{SRMR} \leq .10$ \\
\hline${ }^{5} \mathrm{PNFI}$ & $.95 \leq \mathrm{PNFI} \leq 1.00$ & $.50 \leq \mathrm{PNFI} \leq .95$ \\
\hline${ }^{6} \mathrm{PGFI}$ & $.95 \leq \mathrm{PNFI} \leq 1.00$ & $.50 \leq \mathrm{PNFI} \leq .95$ \\
\hline
\end{tabular}

${ }^{1}$ (Kline, 2005), ${ }^{2}$ (Schermelleh-Engel ve Moosbrugger, 2003), ${ }^{3}$ (Baumgartner ve Homburg, 1996; Bentler, 1980; Bentler ve Bonett, 2004; Marsh ve ark., 2006), ${ }^{4}$ (Browne ve Cudeck, 1992), ${ }^{5}$ Hu ve Bentler, 1999), ${ }^{6}$ (Meyers ve ark., 2006). 
Yerlisu Lapa, T., \& Tercan Kaas, E. (2019 Serbest Zamanda Algilanan Özgürlük Ölçeği-25: Üniversite öğrencileri için yap1 geçerliğinin sinanması. Journal of Human Sciences, 16(4), 1071-1083. doi:10.14687/jhs.v16i4.5860

\section{Bulgular}

Araştırma bulguları verilirken geçerlik ve güvenirlik analizi olmak üzere iki başlık altında değerlendirilmiştir.

\section{Ölçeğin Geçerliğine İlişkin Bulgular}

\section{Yapı geçerliği}

Witt ve Ellis (1985) serbest zamanda algılanan özgürlük ölçeğine ilişkin yaptıkları DFA analizi ile ölçeğin tek boyutlu olduğunu ortaya koymuşlardır. Witt ve Ellis (1985)'in ortaya koyduğu yapıyı test etmek amacıyla yapılan ilk DFA analiz sonuçları AGFI ve GFI uyum indekslerinin refere edilen değerler içinde yer almadığını göstermektedir. Ancak GFI uyum indeksinin örneklem büyüklügünnden etkilendiği göz önüne alındığında düşük çıkmasının manidar olduğu düşünülmektedir (Cheung ve Rensvold, 2000; Wu ve ark., 2007). Diğer uyum indeksleri incelendiğinde ise; RMSEA değerinin kabul edilebilir uyum ölçütleri arasında yer aldığı buna karşın $\chi^{2} / d f$, NFI, TLI ve CFI değerlerinin ise mükemmel uyum ölçütlerini karşıladığı tespit edilmiştir.

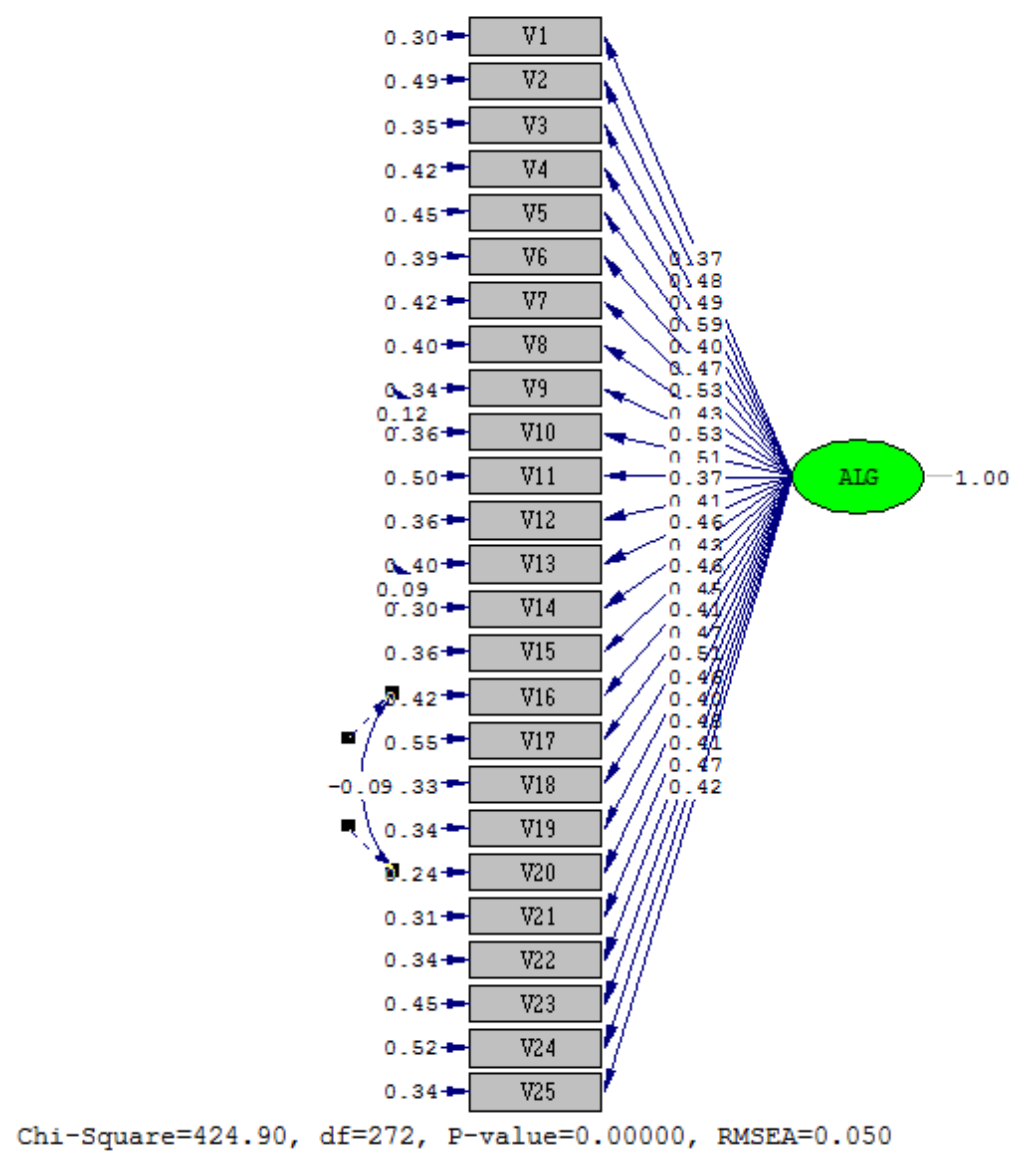

\section{Şekil 1. Serbest Zamanda Algılanan Özgürlük Ölçeği Doğrulayıc1 Faktör Analizi}

Ancak AGFI değerinin düşük olması ve ilgili modifikasyon önerileri de dikkate alınarak yüksek hata kovaryanslarına sahip maddeler birbirleri ile eşleştirilmiştir (e9-e10, e13-e14, e16-e20). Modifikasyon sonrasında yapılan uyum indekslerine ilişkin sonuçlar Tablo 3'de verilmektedir. Yapılan DFA analizi sonrası maddelerin ilgili faktörleri \%09 güven aralı̆̆ında doğruladığ ifade edilebilir $(\mathrm{p}=.000)$. 
Yerlisu Lapa, T., \& Tercan Kaas, E. (2019 Serbest Zamanda Algilanan Özgürlük Ölçeği-25: Üniversite öğrencileri için yap1 geçerliğinin sinanması. Journal of Human Sciences, 16(4), 1071-1083. doi:10.14687/ihs.v16i4.5860

Tablo 3. Doğrulayıc1 Faktör Analizi Uyum İndeksleri

\begin{tabular}{cccccccccc}
\hline & $\chi^{2}$ & $\boldsymbol{d f}$ & $\begin{array}{c}\chi^{2} / \boldsymbol{d} \\
\boldsymbol{f}\end{array}$ & AGFI & GFI & NFI & TLI & CFI & RMSEA \\
\hline $\begin{array}{c}\text { Modifikasyondan } \\
\text { önce }\end{array}$ & 497.33 & 275 & 1.80 & .82 & .85 & .95 & .98 & .98 & .060 \\
$\begin{array}{c}\text { Modifikasyondan } \\
\text { sonra }\end{array}$ & 424.90 & 272 & 1.56 & .85 & .87 & .95 & .98 & .98 & .050 \\
\hline
\end{tabular}

Araşturmanın bir sonraki aşamasında maddelerin örtük yapıya katkıları değerlendirilmiş bu bağlamda maddelerin standart yükleri ile ve örtük değişkeni açıklamada manidarlık düzeyleri verilmiştir. Serbest zamanda algilanan ölçeğine ilişkinin maddeler incelendiğinde örtük değişkeni en fazla açılayan maddenin 20. Madde olduğu "Rekreasyon aktivitelerini yaparken iyi şeylerin olmasını sağlarım" ve en az açıklayan maddenin ise 11. Madde "Genelde rekreasyon aktivitelerini kiminle yapacağıma kendim karar veririm” olduğu tespit edilmiştir. Ölçek maddelerine ilişkin standartlaştırılmış yükler, t ve $\mathrm{r}^{2}$ değerleri Tablo 4'de detaylı olarak verilmektedir.

Tablo 4. Serbest Zamanda Algılanan Özgürlük Ölçeğine Ait Ölçme Modeli Sonucu

\begin{tabular}{cccc}
\hline Faktör Madde & Standartlaştırllmiş Yükler & t-değeri & $\mathrm{R}^{2}$ \\
\hline SZAÖ1 & 0.56 & 8.97 & 0.32 \\
SZAÖ2 & 0.57 & 9.02 & 0.32 \\
SZAÖ3 & 0.64 & 10.51 & 0.41 \\
SZAÖ4 & 0.67 & 11.19 & 0.45 \\
SZAÖ5 & 0.51 & 7.92 & 0.26 \\
SZAÖ6 & 0.60 & 9.72 & 0.36 \\
SZAÖ7 & 0.63 & 10.39 & 0.40 \\
SZAÖ8 & 0.56 & 9.00 & 0.32 \\
SZAÖ9 & 0.67 & 11.16 & 0.45 \\
SZAÖ10 & 0.65 & 10.65 & 0.42 \\
SZAÖ11 & 0.47 & 7.20 & 0.22 \\
SZAÖ12 & 0.56 & 8.95 & 0.32 \\
SZAÖ13 & 0.59 & 9.41 & 0.34 \\
SZAÖ14 & 0.62 & 10.11 & 0.39 \\
SZAÖ15 & 0.61 & 9.82 & 0.37 \\
SZAÖ16 & 0.57 & 9.03 & 0.32 \\
SZAÖ17 & 0.49 & 7.56 & 0.24 \\
SZAÖ18 & 0.63 & 10.30 & 0.40 \\
SZAÖ19 & 0.65 & 10.81 & 0.43 \\
SZAÖ20 & 0.68 & 11.35 & 0.46 \\
SZAÖ21 & 0.58 & 9.29 & 0.34 \\
SZAÖ22 & 0.64 & 10.48 & 0.41 \\
SZAÖ23 & 0.52 & 8.25 & 0.28 \\
SZAÖ24 & 0.55 & 8.73 & 0.30 \\
SZAÖ25 & 0.58 & 9.37 & 0.34 \\
\hline
\end{tabular}

sunulacaktır.

Çalışmanın bundan sonraki aşamasında ilgili çalısmaya yönelik güvenirlik kanıtları 
Yerlisu Lapa, T., \& Tercan Kaas, E. (2019 Serbest Zamanda Alg1lanan Özgürlük Ölçeği-25: Üniversite öğrencileri için yap1 geçerliğinin sinanması. Journal of Human Sciences, 16(4), 1071-1083. doi:10.14687/ihs.v16i4.5860

\section{Güvenirliğe İlişkin Bulgular}

Yapılan çalışmada DFA analizi sonucu serbest zamanda algilanan özgürlük ölçeğine ilişkin Cronbach Alfa iç tutarlılık katsayısı hesaplanmıştır. Ölçek tek alt boyutlu olup güvenirlik kat sayısının 0.93 olduğu saptanmiştır.

\section{Tartışma ve Sonuç}

Bu çalışma, Witt ve Ellis (1985) tarafindan geliştirilen, Yerlisu Lapa ve Ağyar (2011) tarafindan Türkçe adaptasyonu yapılan “Serbest Zamanda Algılanan Özgürlük Ölçeği’nin geçerliliğini doğrulayıcı faktör analizi ile sınamak amacıyla yapılmıştır.

Serbest Zamanda Algılanan Özgürlük Ölçeği’ın 2011 yıllnda Yerlisu Lapa ve Ağyar tarafindan dil geçerliği ve açımlayıcı faktör analizi ile sınanan 25 maddeden oluşan ve tek faktörlü yapısının geçerliği için, doğrulayıcı faktör analizi uygulanmıştır. Doğrulayıcı faktör analizi sonucu, modifikasyon endekslerine bakılarak yüksek hata kovaryanslarnna sahip maddeler birbirleri ile eşleştirilmiştir (e9-e10, e13-e14, e16-e20). Eşleştirme sonrası AGFI=0.85, GFI=0.87, NFI=0.95, TLI $=0.98$, CFI $=0.98$ ve RMSEA $=0.050$ sonuçlarına göre ölçek modelinin gözlenen değerleri (Anderson ve Gerbing, 1988; Hooper ve ark., 2008; Hu ve Bentler, 1999; Schermelleh-Engel ve Moosbrugger, 2003; Sümer, 2000), ölçeğin tek faktörlü yapısının kabul edilebilir ve geçerli sonuçlar verdiğini göstermektedir.

Serbest Zamanda Algılanan Özgürlük Ölçeği’in güvenirlik çalışmaları sonuçlarına bakıldığında ise; Cronbach Alfa katsayısının 0.93 ile $\geq 0.70$ (Nunnally and Bernstein, 1994) olduğu, bu nedenle ölçeğin güvenirlik bakımından yeterli olduğu söylenebilir.

Araştırmada elde edilen bulgular sonucunda, 25 madde ve tek faktörden oluşan Serbest Zamanda Algılanan Özgürlük Ölçeği’nin, geçerli ve güvenilir bir ölçüm arac1 olarak serbest zaman araştırmalarında kullanılabileceği söylenebilir.

Bu çalışmanın en önemli sınırlılığı ise elde edilen verilerin sadece tek bir üniversite ile sınırlı olmasıdır. İleriki çalışmalarda serbest zamanda algılanan özgürlük ölçeğinin uyum geçerliliğini belirlemek amacıyla, başka ölçeklerle arasındaki korelasyonların incelenmesi, ölçeğin farklı örneklem grupları üzerinde (örn. çalışan bireyler) tekrar doğrulayıcı faktör analizi ile doğrulanması faydalı olacağı düşünülmektedir. Son olarak, bu ölçeğin kullanılabileceği araştırmaların yapılması ölçme gücüne önemli katkılar sağlayacaktır.

\section{Kaynaklar}

Agyar, E. (2014). Contribution of perceived freedom and leisure satisfaction to life satisfaction in a sample of Turkish women. Social Indicators Research, 116, 1-15.

Anderson. J. \& Gerbing, D. (1988). Structural equation modeling in practice: A review and recommended two-step approach. Psychological Bulletin, 103(3), 411-423.

Baumgartner, H. \& Homburg, C. (1996). Applications of structural equation modeling in marketing and consumer research: A review. International Journal of Research in Marketing, 13 (2), 139-161.

Bentler, P.M. \& Bonett, D.G. (2004). Significance tests and goodness of fit in the analysis of covariance structures. Psychological Bulletin, 88, 588-606.

Bentler, P.M. (1980). Multivariate analysis with latent variables: Causal modeling. Annual Review of Psychology, 31, 419-456.

Browne, M.W. \& Cudeck, R. (1992). Alternative ways of assessing model fit. Social Methods \& Research, 21 (2), 230-258.

Büyüköztürk, Ş., Çakmak, E. K., Akgün, Ö. E., Karadeniz, Ş., \& Demirel, F. (2014). Bilimsel Arastrma Yöntemleri (17.Baskı). Ankara: Pegem Akademi.

Carter, S.E. (1995). The effect of selected leisure variables on the independent leisure functioning of adults with mental retardation who participate in two North Carolina community college compensatory education programmes. Doctoral Dissertation, North Carolina State University, North Carolina. 
Yerlisu Lapa, T., \& Tercan Kaas, E. (2019 Serbest Zamanda Alg1lanan Özgürlük Ölçeği-25: Üniversite öğrencileri için yap1 geçerliğinin sinanması. Journal of Human Sciences, 16(4), 1071-1083. doi:10.14687/jhs.v16i4.5860

Cheung, G.W. \& Rensvold, R.B. (2000). Assessing extreme and acquiescence response sets in cross-cultural research using structural equations modeling. Journal of Cross-Cultural Psychology, 31 (2), 187-212.

Comrey, A.L. \& Lee, H.B. (1992). A First Course in Factor Analysis (Second Edition). Hillsdale, NJ, US: Lawrence Erlbaum Associates, Inc.

Deci, E. (1975) Intrinsic Motivation. New York, Plenum Press.

Ellis, G.D. \& Witt, P.A. (1984). The measurement of perceived freedom in leisure. Journal of Leisure Research, 16, 110-123.

Guinn, B., Semper, T. \& Jorgensen, L. (1996). Perceived leisure freedom and activity involvement among Mexican American adolescents. Hispanic Journal of Behavioral Sciences, 18 (3), 356-366.

Günbayı, İ. \& Sorm, S. (2018). Social paradigms in guiding social research design: The functional, interpretive, radical humanist and radical structural paradigms. International Journal on New Trends in Education and Their Implications, 9 (2), 57-76.

Hambleton, R.K. \& Patsula, L. (1999). Increasing the validity of adapted tests: Myths to be avoided and guidelines for improving test adaptation practices. Journal of Applied Testing Technology, 1 (1), $1-30$.

Harmandar Demirel, D., Demirel, M. \& Serdar, E. (2017). University students' opinions of the meaning of leisure and their perceived freedom in leisure. Journal of Human Sciences, 14 (1), 796-802.

Hemingway, J.J. (1996). Emancipating leisure: The recovery of freedom in leisure. Journal of Leisure Research, 28 (1), 27-35.

Hooper, D., Coughlan, J. \& Mullen, M.R. (2008). Structural equation modelling: Guidelines for determining model fit. Electronic Journal of Business Research Methods, 6 (1), 53-60.

Hu, L-t., \& Bentler, P.M. (1999). Cutoff criteria for fit indexes in covariance structure analysis: Conventional criteria versus new alternatives. Structural Equation Modeling: A Multidisciplinary Journal, 6 (1), 1-55.

Kim, B. (2010). A conceptual framework for leisure and subjective well-being. International Journal of Tourism Sciences, 10 (2), 85-116.

Kline, R.B. (2005). Principles and Practice of Structural Equation Modeling (Second Edition). NY: Guildford Publications Inc.

Marsh, H.W., Kit-Tai, H., Artelt, C., Baumert, J., \& Peschar, J.L. (2006). OECD’s brief self-report measure of educational psychology's most useful affective constructs: Cross-cultural, psychometric comparisons across 25 countries. International Journal of Testing, 6 (4), 311-360.

Meyers, L.S., Gamst, G. \& Guarino, A. (2006). Applied Multivariate Research: Design and Interpretation (Third Edition). London: SAGE publishing.

Munchua, M.M., Lesage, D.M., Reddon, J.R. \& Badham, T.D. (2003). Motivation, satisfaction and perceived freedom: A Tri-dimensional model of leisure among young offenders. Journal of Offender Rebabilitation, 38 (1), 53-64.

Munson, W.W. (1993). Perceived freedom in leisure and career salience in adolescence. Journal of Leisure Research, 25 (3), 305-314.

Naito, J. (2007). Perceived freedom and its sociological effects: An inquiry into the relationship between liberalism and inequality. International Journal of Japanese Sociology, 16, 80-99.

Nunnally, J.C. \& Bernstein, I.H. (1994). The assessment of reliability. Psychometric Theory, 3, 248-292.

Poulsen, A.A., Ziviani, J.M. \& Cuskelly, M. (2007). Perceived freedom in leisure and physical coordination ability: impact on out-of-school activity participation and life satisfaction. Child Care, Health and Development, 33 (4), 432-440

Poulsen, A.A., Ziviani, J.M., Johnson, H. \& Cuskelly, M. (2008). Loneliness and life satisfaction of boys with developmental coordination disorder: The impact of leisure participation and perceived freedom in leisure. Human Movement Science, 27, 325-343.

Ravid, R. (1994). Practical Statistics for Educators. New York: University Press in America. 
Yerlisu Lapa, T., \& Tercan Kaas, E. (2019 Serbest Zamanda Alg1lanan Özgürlük Ölçeği-25: Üniversite öğrencileri için yap1 geçerliğinin sinanması. Journal of Human Sciences, 16(4), 1071-1083. doi:10.14687/ihs.v16i4.5860

Rosenthal, R. \& Rosnow, R.L. (2008). Essential of Behavioral Research. Methods and Data Analysis (Third Editon). New York: McGraw-Hill. file://C:/Users/ares/Downloads/EssentialsofBehavioralResearch.pdf

Schermelleh-Engel, K., \& Moosbrugger, H. (2003). Evaluating the fit of structural equation models: Tests of significance and descriptive goodness-of-fit measures. Methods of Psychological Research Online, 8 (2), 23-74.

Seçer, İ. (2015). SPSS ve LISREL ile Pratik Veri Analizi: Analiz ve Raporlastrma. Ankara: Anı Yayınc1lik.

Siegenthaler, K.L. \& O'Dell, I. (2000). Leisure attitude, leisure satisfaction and perceived freedom in leisure within family dyads. Leisure Sciences, 22, 281-296.

Spielberger, C.D., Merenda, P.F. \& Hambleton, R.K. (2017). Eğitimde ve Psikolojide Kullanulan Testlerin Kültürlerarası Değerlendirme Amacıyla Uyarlanması. (Çev: Nizamettin Koç \& Ahmet Yıldırım). Ankara: Pegem Akademi.

Stelzer, J. (2000). The Relationship between Perceived Freedom in Leisure and Delinquency Behaviours in Middle School Students. Doctoral Dissertation. University of New Mexico.

Sümer, N. (2000). Yapısal eşitlik modelleri: Temel kavramlar ve örnek uygulamalar. Türk Psikoloji Yažlar, 3 (6), 49-74.

Tabachnick, B., \& Fidell, L. S. (2007). Çok Değğskenli İstatistiklerin Kullanımı. Ankara: Nobel Akademik Yayıncilik.

Witt, P.A. \& Ellis, G.D. (1985). Development of a short form to assess perceived freedom in leisure. Journal of Leisure Research, 17 (3), 225-223.

Wu, A.D., Li, Z. \& Zumbo, B.D. (2007). Decoding the meaning of factorial invariance and updating the practice of multi-group confirmatory factor analysis: A demonstration with TIMSS data. Practical Assesment, Research \& Evaluation, 12 (3), 1-26.

Wu, H.C., Liu A. \& Wang, C-H. (2010). Taiwanese university students' perceived freedom and participation in leisure. Annals of Leisure Research, 13 (4), 679-700.

Yerlisu Lapa, T. \& Ağyar E., (2011). Cross cultural adaptation of perceived freedom in leisure scale. World Applied Sciences Journal, 14 (7), 980-926.

Yerlisu Lapa, T. \& Ağyar, E. (2012). Üniversite öğrencilerinin serbest zaman katıllmlarına göre algilanan özgürlük. Spor Bilimleri Dergisi, 23 (1), 24-33.

Yerlisu Lapa, T. (2013). Life satisfaction, leisure satisfaction and perceived freedom of park recreation participants. Procedia - Social and Behavioral Sciences, 93, 1985-1993.

Yerlisu Lapa, T., Köse, E. \& Günbayı, İ. (2018). Türkiye'de yapılan Rekreasyon Araştırmaları: Sistematik bir Derleme. Spor Bilimleri Dergisi, 29 (2), 87-104.

\section{Extended English Summary}

Leisure behaviour is an important study area of the literature recently. In apprehending leisure behaviour, perceived freedom in leisure is a significant dimension (Wu et al., 2010). The relationship of leisure was examined with the concept of freedom which is one of the basic values of contemporary societies (Naito, 2007), since Aristotle defined leisure as being free from the requirements of working and leisure was thought to have a special aim and an action with virtue (Hemingway, 1996). The identification of perceived freedom as a control variable affecting human behaviour was expanded further by Heider who recommended perceived freedom as a useful tool to predict human behaviour and clearly stated that human behaviour was determined by individual's feeling of perceived freedom (Wu et al., 2010). The concept of perceived freedom was expressed by Ellis and Witt (1984) and also Neulinger as basic criteria of leisure and Neulinger defined leisure as a situation where an individual performs an action willingly, by his/her own decision (Siegenthaler and O'Dell, 2000). The relationship between perceived freedom and leisure was tested empirically for instance in studies conducted by Iso-Ahola perceived freedom was found 
Yerlisu Lapa, T., \& Tercan Kaas, E. (2019 Serbest Zamanda Alg1lanan Özgürlük Ölçeği-25: Üniversite öğrencileri için yap1 geçerliğinin sinanması. Journal of Human Sciences, 16(4), 1071-1083. doi:10.14687/ihs.v16i4.5860

to be determinant in rating the quality of leisure experience of participants or in deciding to participate or not (Ellis and Witt, 1984). As studies concerning leisure and recreation are still less than sufficient and newly developing in Turkey, the need for studies concerning scale development or adaptation increases (Yerlisu Lapa et al., 2018). Although developing a measurement tool specific to the culture is a more preferable method, the insufficiency in the number of experts in the area of the psychometrical traits that the researchers are interested directs them more to adaptation studies (Büyüköztürk, et al., 2014, p. 105). This situation could be seen as one of the reasons why researchers in Turkey are more going towards scale adaptation than developing measurement scales. "Perceived freedom in leisure" developed by Witt and Ellis (1985) and adapted to Turkish by Yerlisu Lapa and Ağyar (2011) is one of these adaptation studies. When it is considered that science is not a stationary process, the changes in the perspectives of researches and diversification of the statistical techniques due to technological developments necessitate further validation of some adaptation studies (Spielberger et al., 2017). Therefore the further validation of the aforementioned scale was found to be appropriate in the light of these arguments and because of the possibility of the concept which is to be measured to change in time because of causing some cultural changes in time.

Study group of this descriptive research consists of 105 women and 123 men making a total of 228 university students. Ages of the participants change between18-26 and mean age is 19.82 1.41. Perceived Freedom in Leisure Scale (PFLS) developed by Witt and Ellis (1985) and adapted to Turkish by Yerlisu Lapa and Ağyar (2011) was used as data collection tool. The original scale consisted of 25 items with one factor. The Turkish version, however consists of 17 items with two factors. Under the first factor named "Knowledge and skills" 9 items, and the second factor named "excitement and amusement" 8 items take place. Scale was in 5 th Likert form such as (1) I totally disagree (2) I disagree (3) uncertain (4) agree (5) totally agree. The factor structure of the scale is displayed by confirmatory factor analysis. Reliability of the scale was calculated by an internal consistency coefficient Cronbach's Alpha $(\alpha)$.

In this study, confirmatory factor analysis was conducted in order to test the factor structure of PFLS developed by Witt and Ellis (1985) with 25 items and one factor. Confirmatory factor analysis was applied by LISREL package programme. As a result of the confirmatory factor analysis, modification indexes were examined and items with high error covariances were matched (e9-e10, e13-e14, e16-e20). After the modification the results of the first level factor analysis were as follows: $\chi^{2} / d f\left(\chi^{2} / d f=1.56\right)$ and other fit indexes: AGFI $=0.85$, GFI $=0.87, \mathrm{NFI}=0.95$, TLI $=0.98$, $\mathrm{CFI}=0.98$ and RMSEA $=0.050$. According to these results the observed values of the scale model (Anderson and Gerbing, 1988; Hooper et al., 2008; Hu and Bentler, 1999; Schermelleh-Engel et al., 2003; Sumer, 2000), show that the one-factor structure of the scale is acceptable and gives valid results. Item factor loadings were between 0.47-0.68. Cronbach's alpha reliability coefficient was found as 0.93 consequently, after the findings, PFLS could be declared to be used in leisure research as a valid and reliable measurement tool with its 25 items and one-factor structure.

The most important limitation of this study is that the data collected were restricted to only one university. For future studies, it is recommended to make a correlation analysis with other scales for testing the concurrent validity of perceived freedom in leisure scale, to conduct this scale on different samples (e.g. employees) and further validate this scale with confirmatory factor analysis for different samples. Finally, conducting more studies using this scale would contribute to the measurement power of the scale. 